\title{
Nanoparticles of Chitosan/Poly(D,L-Lactide-Co- Glycolide) Enhanced the Immune Responses of Haemonchus contortus HCA59 Antigen in Model Mice
}

\author{
Qiangqiang Wang \\ Xiaoke Sun \\ Xin Huang \\ Jianmei Huang \\ Muhammad Waqqas Hasan \\ RuoFeng Yan \\ Lixin Xu \\ Xiaokai Song \\ Xiangrui Li (D)
}

MOE Joint International Research Laboratory of Animal Health and Food Safety, College of Veterinary Medicine, Nanjing Agricultural University, Nanjing, Jiangsu, People's Republic of China
Correspondence: Xiangrui Li MOE Joint International Research Laboratory of Animal Health and Food Safety, College of Veterinary Medicine, Nanjing Agricultural University, No. I Weigang, Nanjing, 210095, Jiangsu

Province, People's Republic of China

$\mathrm{Tel} / \mathrm{Fax}+862584399000$

Email lixiangrui@njau.edu.cn
Background: Hepatocellular carcinoma-associated antigen 59 (HCA59) from excretory/ secretory products of Haemonchus contortus is known to have the ability to modulate the functions of host cells. However, its immunogenicities using different nanoparticles adjuvants remain poorly understood.

Purpose: The study aimed to select an efficient nanoparticle antigen delivery system, which could enhance the immune responses of Haemonchus contortus HCA59 in mice.

Methods: Here, the immune responses induced by the recombinant protein of HCA59 (rHCA59) with poly-D,L-lactide-co-glycolide (PLGA) nanoparticles, Chitosan nanoparticles, mixture of PLGA and Chitosan nanoparticles (rHCA59-Chitosan-PLGA), and Freund's complete adjuvant were observed, respectively, in mice. Cytokine and antibody levels induced by different groups were detected by ELISA assay. The effects of lymphocyte proliferations on different groups were examined using CCK-8 kit. Phenotypes of T cells and dendritic cells were analyzed by flow cytometry.

Results: On day 14 post vaccination, levels of IgM, IgG1, IgG2a, IFN- $\gamma$, IL-4, and IL-17 were significantly increased in the groups immunized with rHCA59 encapsulated with nanoparticles. After mice were vaccinated with rHCA59 loaded with Chitosan/PLGA nanoparticles, lymphocytes proliferated significantly. Additionally, the percentages of $\mathrm{CD} 4^{+}$ $\mathrm{T}$ cells $\left(\mathrm{CD}^{+} \mathrm{CD}^{+}\right), \mathrm{CD}^{+} \mathrm{T}$ cells $\left(\mathrm{CD}^{+} \mathrm{CD}^{+}\right)$, and dendritic cells $\left(\mathrm{CD} 11 \mathrm{c}^{+} \mathrm{CD}^{+} 3^{+}\right.$, $\mathrm{CD} 11 \mathrm{c}^{+} \mathrm{CD} 6^{+}$) were obviously up-regulated in the mice immunized with nanoparticles, especially in the rHCA59-Chitosan-PLGA antigen delivery system group.

Conclusion: The findings of this research demonstrated that rHCA59-Chitosan-PLGA antigen delivery system could induce higher immune responses in mice model and indicated that rHCA59 might be a good candidate molecule to develop nanovaccines against Haemonchus contortus in future study.

Keywords: Haemonchus contortus, rHCA59, Chitosan, PLGA, nanovaccines

\section{Introduction}

Haemonchus contortus (H. contortus), a gastrointestinal nematode parasite, causes serious animal health issues and economic losses in small ruminant industry. ${ }^{1}$ The application of anthelmintics is the primary treatment against the infection of $H$. contortus. However, anthelmintics abuse resulted in the drug resistance of the parasite, which forced people to pay more attention to the developments of novel drug and 
vaccines. ${ }^{2}$ Excretory and secretory products (ESPs) are generated and released by the parasites during in vivo and in vitro cultivation. ${ }^{3,4}$ The ESPs could elicit the depression or activation of host immune responses. ${ }^{5-7} H$. contortus excretory and secretory products (HcESPs), which comprised numerous proteins, ${ }^{8}$ could execute different functions, such as host protein degradation, tissue penetration, and the induction of Th9 immune responses. ${ }^{5,9}$ HCA59 protein belonged to telomere length and silencing protein 1 (TLS1) family and was related to the spliceosome. It was overexpressed in multiple cancer cell lines in human. ${ }^{10}$ Additionally, hepatocellular carcinoma associated antigen HCA587, a similar protein to HCA59, had been found to induce strong T cells immune responses. ${ }^{11}$

Currently, several vaccination strategies, such as protein vaccines, DNA vaccines, and subunit vaccines, had been studied for protections against $H$. contortus. ${ }^{12}$ The adjuvants or delivery systems of vaccines play significant roles in the protection of vaccines. ${ }^{13}$ Traditional adjuvants, like complete Freund's adjuvant (CFA) and incomplete Freund's adjuvant, have been widely used and are recognized as a gold standard with respect to their high adjuvant activities. ${ }^{14}$ However, owing to the intense local reactions at the injection sites and possible residues in meat, their applications in food animals are restricted. Hence, potent and well-tolerated adjuvant systems for the development of food animal vaccines are required. Nanoparticle (NP)-based delivery systems target immune cells effectively in vivo. Owing to the particle size and the subsequent wide bio-distribution profile, the usage of NPs in vaccines presents definite distinctive advantages over the traditional delivery systems. ${ }^{15}$ The biodegradable and biocompatible polymeric NP carriers hold the properties of controlled release and adjustable sub-cellular size, ${ }^{16,17}$ and can prolong the time of antigen exposure to immunocytes, facilitate dendritic cells (DCs) to uptake the antigens, adjust antigen presentation ways, and consequently improve immune responses. Earlier studies indicated that PLGA adjuvant could be beneficial to the development of vaccines. ${ }^{18}$ Recently, it was identified that the encapsulated soluble Leishmania infantum antigens loaded with PLGA could elicit strong immune responses and various L. infantum proteins could induce the maturation of DC and produce obvious protection against visceral leishmaniasis in mice. ${ }^{19,20}$ During the past decade, Chitosan-based delivery system used as an adjuvant matrix had become more and more appealing. ${ }^{21,22}$ It was reported that the immunogenicity of Leishmania superoxide dismutase loaded with Chitosan was increased and levels of defense against infection with Leishmania were improved in mice. ${ }^{23}$
In previous studies, it was demonstrated that rHCA59 could bind to the PBMCs and DCs of goats and the differentiation and maturation of DCs were significantly increased. ${ }^{24}$ In the present study, the polymers PLGA and Chitosan (CS) were used as adjuvant carrier systems to explore the immunogenicity of rHCA59 in model mice. Data in this research would be beneficial to the development of nanovaccines against $H$. contortus infections.

\section{Materials and Methods}

\section{Animals and Protein}

Specific-pathogen-free female ICR mice (body weight 18-20 g) were purchased from the Experimental Animal Center of Jiangsu, PR China (Qualified Certificate: SCXK 2017-0001) and were kept under the specific pathogenfree (SPF) conditions with sterilized food and water.

The purified recombinant protein HCA59 expressed in Escherichia coli using pET-32a vector was from Nanjing Agricultural University Parasite Laboratory and the information about gene cloning and expression about HCA59 could be obtained from the previous work. ${ }^{24}$ The pET-32a protein was produced from the Escherichia coli transformed with pET-32a using the same method.

Mice used in this experiment were handled according to the guidelines of the Animal Ethics Committee, Nanjing Agricultural University, China. All animal experiments complied with the guidelines of the Animal Welfare Council of China. All experimental protocols were approved by the Science and Technology Agency of Jiangsu Province. The approval ID is SYXK (SU) 2010-0005.

\section{Optimizing of the Concentration of Polyvinyl Alcohol}

In the preparation of PLGA (Sigma Aldrich, St. Louis, MI, USA) nanoparticles, polyvinyl alcohol (PVA) (Sigma Aldrich, St. Louis, MI, USA) played a significant role as a surfactant. Therefore, the working concentration of PVA was investigated before starting the preparation of nanoparticles. Three PVA concentration gradients were designed, which were $1 \%, 4 \%$, and $6 \%$, respectively. The characterizations of PLGA NPs using different PVA concentrations were observed by a scanning electron microscopy (JEOL, Akishima-shi, Tokyo, Japan).

\section{Preparation of rHCA59-Loaded PLGA NPs}

Polymeric nanoparticles were prepared under aseptic condition according to the double emulsion (w/o/w) solvent 
evaporation method. ${ }^{25}$ Briefly, the protein $\mathrm{rHCA} 59(1 \mathrm{mg} / \mathrm{mL})$ was dissolved in $6 \%(\mathrm{w} / \mathrm{v})$ PVA solution to form the inner aqueous phase ( $2 \mathrm{mg}$ protein in $2 \mathrm{~mL}$ PVA solution). The organic phase was obtained by dissolving $5 \%(\mathrm{w} / \mathrm{v})$ PLGA in methylene chloride $(50 \mathrm{mg}$ PLGA in $1 \mathrm{~mL}$ methylene chloride). To form the w/o emulsion, the aqueous phase and organic phase were combined and sonicated using an ultrasonic processor (Scientz Biotechnology, Ningbo, Zhejiang, China) in an ice bath for $4 \mathrm{~min}(40 \mathrm{w}, 5 \mathrm{~s}, 5 \mathrm{~s})$. Thereafter, the w/o emulsion was transferred into the external aqueous phase containing $6 \%$ (w/v) PVA dissolved in deionized water, followed by sonicating for $4 \mathrm{~min}(40 \mathrm{w}, 5 \mathrm{~s}, 5 \mathrm{~s})$ to obtain the final w/o/w emulsion. Finally, the organic solvent was evaporated for $4 \mathrm{~h}$ under stirring at room temperature to form the nanoparticles. The solution of nanoparticles was centrifuged at $20,000 \times \mathrm{g}$ for 40 $\min$ at $4{ }^{\circ} \mathrm{C}$; then, the supernatant was collected for the calculation of protein loading efficiency using a BCA protein assay kit (Cwbiotech, Beijing, China) and the precipitated nanoparticles were washed twice with ultrapure water by centrifugation. After that, the nanoparticles were placed in a freeze-drying machine for $24 \mathrm{~h}$ and subsequently stored at $-80{ }^{\circ} \mathrm{C}$ until use. The preparations of empty PLGA NPs were similar to the method of rHCA59-loaded PLGA NPs except for adding the protein rHCA59.

\section{Preparation of rHCA59-Loaded Chitosan NPs}

The rHCA59-loaded Chitosan NPs were prepared using the ionic gelation method. ${ }^{26-29}$ Briefly, in order to prepare Chitosan solution (2 mg/mL), Chitosan (200 mg) (Sigma Aldrich, St. Louis, MI, USA) was dissolved in a final volume of $100 \mathrm{~mL} \mathrm{1 \%}$ acetic acid and stirred at room temperature for $30 \mathrm{~min}$. The solution $\mathrm{pH}$ was adjusted to 5.0 using $2.0 \mathrm{~N} \mathrm{NaOH}$ in $30 \mathrm{~min}$. A total of $2 \mathrm{mg}$ rHCA59 protein was added to $5.7 \mathrm{~mL}$ Chitosan solution drop by drop for $10 \mathrm{~min}$ until the final concentration of the antigen reached $0.3 \mathrm{mg} / \mathrm{mL}$. After that, a volume of $4 \mathrm{~mL}$ sodium tripolyphosphate (TPP) (Aladdin, Shanghai, China) was added to the Chitosan antigen solution with continuous magnetic stirring at room temperature. Afterwards, the mixture was sonicated for $4 \mathrm{~min}(50 \mathrm{w}, 5 \mathrm{~s}, 5 \mathrm{~s})$. The formulated rHCA59 nanoparticles was centrifuged at $20,000 \times \mathrm{g}$ for $40 \mathrm{~min}$ and subsequently the supernatant was collected for the calculation of protein loading efficiency using a BCA protein assay kit and the precipitated nanoparticles were washed two times with ultrapure water by centrifugation. Finally, the nanoparticles were frozen in a freeze-drying machine for $24 \mathrm{~h}$ and then stored at $-80{ }^{\circ} \mathrm{C}$ until use. The empty Chitosan NPs (CS NPs) were prepared similar to the method of rHCA59-loaded Chitosan NPs except for adding the protein rHCA59.

\section{Preparation of rHCA59-Loaded Freund's Adjuvant}

Purified protein rHCA59 (2 mg) was firstly mixed with PBS to $2500 \mu \mathrm{L}$ and subsequently mixed with CFA at a ratio of $1: 1$. Here, the same volume of PBS to the protein was used as a control.

\section{Characterization of rHCA59-Loaded PLGA and Chitosan NPs}

Protein loading efficiency of rHCA59-PLGA NPs/rHCA59CS NPs was estimated indirectly by calculating the difference between the initial amount of protein used for loading Chitosan/PLGA NPs and protein left in the supernatant. ${ }^{29,30}$

$$
\mathrm{EE}(\%)=\frac{(\mathrm{W} 1-\mathrm{W} 2)}{\mathrm{W} 1} \times 100 \%
$$

In this formula, $\mathrm{W} 1$ is the total amount of rHCA59 added and W2 is the amount of free rHCA59 in the supernatant. The morphology and size of PLGA NPs were observed using a cold field emission JEOL IT-100 scanning electron microscope (JEOL, Akishima-shi, Tokyo, Japan) and the apparent form of Chitosan NPs was observed by an S-3000N scanning electron microscope (Hitachi, Chiyoda$\mathrm{ku}$, Tokyo, Japan). Briefly, the powder form of NPs was mounted onto aluminum stubs and coated with platinum prior to examination under the microscope.

\section{Vaccination}

Mice were assigned randomly to ten groups of eight mice per group and vaccinated only once on day 0 . On day 14 , mice were euthanized. The PBS group was injected with $1 \mathrm{~mL}$ PBS and the pET-32a protein group was injected with $20 \mu \mathrm{g}$ pET32a protein in PBS. The PBS-CS group, PBS-PLGA group, and PBS-CFA group were vaccinated with $25 \mathrm{mg} \mathrm{CS}, 6.25 \mathrm{mg}$ PLGA, and 50\% CFA in PBS, respectively. The rHCA59 protein group, rHCA59-CFA group, rHCA59-CS group, rHCA59-PLGA group, and rHCA59-CS-PLGA group were immunized with vaccine containing $20 \mu \mathrm{g}$ rHCA59, respectively. Mice in rHCA59-CS-PLGA group were immunized with a mixture of $10 \mu \mathrm{g}$ rHCA59-CS NPs and $10 \mu \mathrm{g}$ rHCA59PLGA NPs. The injection volume in all groups was $1 \mathrm{~mL}$. Subcutaneous immunization was performed by multiple place injections as previously described. ${ }^{31}$ 


\section{Observation of Clinical Signs and Local Reactions}

In order to identify whether the nanoparticles' adjuvant antigen delivery systems could elicit some abnormal changes in mice for two weeks, necropsy lesions, clinical signs, and neurological signs in ten groups were observed and recorded.

\section{Antibody Assays}

Mice sera were collected before sacrifice on day 14 . The levels of $\operatorname{IgG1}$, IgG2a, and IgM in sera were examined using commercially available mouse ELISA kits according to the manufacturer's instructions (HengYuan, Shanghai, China). Briefly, the wells of 96-well microtiter plates were coated with purified rHCA59 protein. Then, mouse sera samples diluted with PBS were added to the wells and incubated for $30 \mathrm{~min}$ at $37{ }^{\circ} \mathrm{C}$. After washing with PBST, the wells were incubated with HRP conjugated anti-mouse antibodies for determination of antibody levels and isotype analysis. After $200 \mu \mathrm{L}$ substrate solutions (A: $\mathrm{H}_{2} \mathrm{O}_{2}, \mathrm{~B}: 3$, 3', 5, 5'-Tetramethylbenzidine) were added, the reaction was terminated with $2 \mathrm{M} \mathrm{H}_{2} \mathrm{SO}_{4}$. Both positive and negative controls were included in each plate. Finally, the results were observed at an absorbance of $450 \mathrm{~nm}$.

\section{Cytokine Assays}

The levels of IL-4, IL-12, IL-17, IFN- $\gamma$, and TGF- $\beta$ in sera from the ten groups were investigated with commercial ELISA kits (HengYuan, Shanghai, China) according to the manufacturer's guidelines.

\section{Splenic Lymphocyte Proliferation Assay}

The splenic lymphocyte proliferation assay was conducted to evaluate the activation of rHCA59-specific lymphocytes. ${ }^{32}$ On day 14, eight mice per group were euthanized and the spleen lymphocytes were isolated using the Mouse Spleen Lymphocyte Isolation Kit (TBD, Tianjin, China) under sterile conditions. The cell concentration was adjusted to $1 \times 10^{7}$ cells $/ \mathrm{mL}$ and subsequently cultured in 6-wells cell plates overnight. After that, cell supernatants ( $T$ cells and B cells) were collected and the concentration of cell was adjusted to $1 \times 10^{6}$ cells $/ \mathrm{mL}$. Next, $1 \times 10^{7}$ cells in $100 \mathrm{uL}$ RPMI -1640 culture medium $(\mathrm{CM})$ supplemented with $10 \%$ heat inactivated fetal calf serum, $100 \mathrm{U} / \mathrm{mL}$ penicillin and $100 \mathrm{mg} / \mathrm{mL}$ streptomycin (Gibco, Carlsbad, CA, USA) were cultured in each well of 96-well culture plates and stimulated with $2 \mu \mathrm{g} /$ $\mathrm{mL}$ rHCA59 for $72 \mathrm{~h}$. In addition, CM-treated cultures without rHCA59 stimulation and with Con A (Sigma Aldrich,
St. Louis, MI, USA) were conducted and applied as a blank control and a positive control, respectively. ${ }^{33}$ The rHCA59induced lymphocyte proliferation was checked using the Enhanced Cell Counting Kit-8 (CCK-8) (Beyotime, Shanghai, China) according to the manufacturer's instructions. The absorbance was measured using a microtiter enzyme-linked immunosorbent assay reader (Thermo Scientific, Waltham, MA, USA) at a wavelength of $450 \mathrm{~nm}$ $\left(\mathrm{A}_{450}\right.$ value). The results were expressed as the stimulation index (SI), based on the following formula: ${ }^{34}$

$$
\mathrm{SI}(\%)=\frac{\mathrm{At}}{\mathrm{Ac}} \times 100 \%
$$

In this formula, $A_{t}$ indicates the mean $A_{450}$ value of the experimental group and $A_{c}$ represents that of the blank control group.

\section{Analysis of Lymphocyte Phenotype}

The method of isolation of $\mathrm{T}$ cells and $\mathrm{B}$ cells from the immunized mice was the same as the splenic lymphocyte proliferation assay. Cells stained with Hamster anti-CD3eAPC and Rat anti-CD4-FITC (Biolegend, San Diego, CA, USA) were detected for the percentage of $\mathrm{CD} 4^{+} \mathrm{T}$ cells. Cells stained with Hamster anti-CD3e-APC and Rat antiCD8a-FITC were examined for the percentage of $\mathrm{CD}^{+}$ $T$ cells. Here, cells stained with antibodies were examined using a fluorescence-activated cell sorting (BD Biosciences, Franklin Lakes, NJ, USA).

\section{Analysis of DC Phenotype}

Spleen cells were firstly isolated using a Mouse Spleen Lymphocyte Isolation kit and subsequently the mixture of cells was cultured overnight. The non-adhering cell supernatant was discarded and the cell plate was washed three times using PBS. After that, the attached cells were collected by pipetting gently and repeatedly, followed by centrifugation, washing, and staining with antibodies. Cells stained with Hamster anti-CD11c-APC and Rat anti-CD83-PE were examined for the percentage of CD83 on DC. Cells stained with Hamster anti-CD11c-APC and Rat anti-CD86-PE were analyzed for the percentage of CD86 on DC. Finally, Analysis of flow cytometry was performed on a BD FACS Calibur flow cytometer (BD Biosciences, Franklin Lakes, NJ, USA).

\section{Statistical Analysis}

All experiments were conducted in triplicate and the data are presented as mean \pm the standard error of mean (SEM). The one-way analysis of variance (ANOVA) test was 
applied to clarify significant differences between groups, and the difference in data significance was set to $* p<$ $0.05, * * p<0.01$, and ${ }^{* * *} p<0.001 .{ }^{35}$ The FACS data analysis was conducted using FlowJo software (version 10, Franklin Lakes, NJ, USA, USA).

\section{Results}

\section{Detection of the Optimal Concentration of PVA}

The particle size and form of PLGA nanoparticles with $1 \%$, $4 \%$, and $6 \%$ PVA were observed, respectively, by scanning electron microscopy. At 6\% PVA, the nanoparticles presented a relatively small particle size, which was generally around $400 \mathrm{~nm}$. However, the particle size was non-uniform at $1 \%$ and $4 \%$ PVA (Figure S1). Therefore, the concentration of $6 \%$ PVA was used in later experiments.

\section{Characterization of rHCA59-CS NPs and rHCA59-PLGA NPs}

After conjugation, PLGA and Chitosan nanoparticles were precipitated and the free amounts of rHCA59 protein were determined by a BCA protein assay kit. It was found that $89 \%$ and $71 \%$ of rHCA59 were conjugated to PLGA and Chitosan, respectively. In other words, a total of $1.78 \mathrm{mg}$ of protein bound to PLGA, and $1.42 \mathrm{mg}$ of protein bound to Chitosan.

A scanning electron microscopy was used to identify the size and morphology of PLGA and Chitosan nanoparticles. The SEM results showed that both PLGA and
Chitosan nanoparticles' appearances were smooth. The size of rHCA59-PLGA NPs was from $180 \mathrm{~nm}$ to $402 \mathrm{~nm}$ (Figure 1A) and the size of rHCA59-CS NPs was from $200 \mathrm{~nm}$ to $500 \mathrm{~nm}$ (Figure 1B).

\section{Evaluation of the Clinical Signs and Local Reactions of the Nanoparticles Vaccination}

During the whole process of experiment, no neurological signs, clinical signs or necropsy lesions were observed in mice immunized with rHCA59-CS NPs, rHCA59-PLGA NPs, rHCA59-CS-PLGA NPs, PBS-CS NPs, and PBSPLGA NPs, indicating that Chitosan and PLGA nanoparticles were well tolerated and presented high level of safety in mice. Mice in PBS-CFA and rHCA59-CFA groups showed low-grade skin redness and swelling $(<1 \mathrm{~cm}$ lesions) at the sites of injection, which identified the side effects of CFA.

\section{Evaluation of the Level of Antibodies Induced by the Four Delivery Systems}

An ELISA assay was conducted to examine the levels of $\operatorname{IgG1}$ IgG2a, and IgM in mice sera among ten groups. As depicted in Figure 2, the levels of IgG1 in rHCA59-PLGA, rHCA59-CS, rHCA59-CS-PLGA, and rHCA59-CFA groups were significantly higher than those in PBS group ( $p<0.001, p<0.001, p<0.001, p<0.001$, respectively) and also significantly higher than those in rHCA59 and pET-32a protein groups $(p<0.01, p<0.01, p<0.001, p<0.05$,

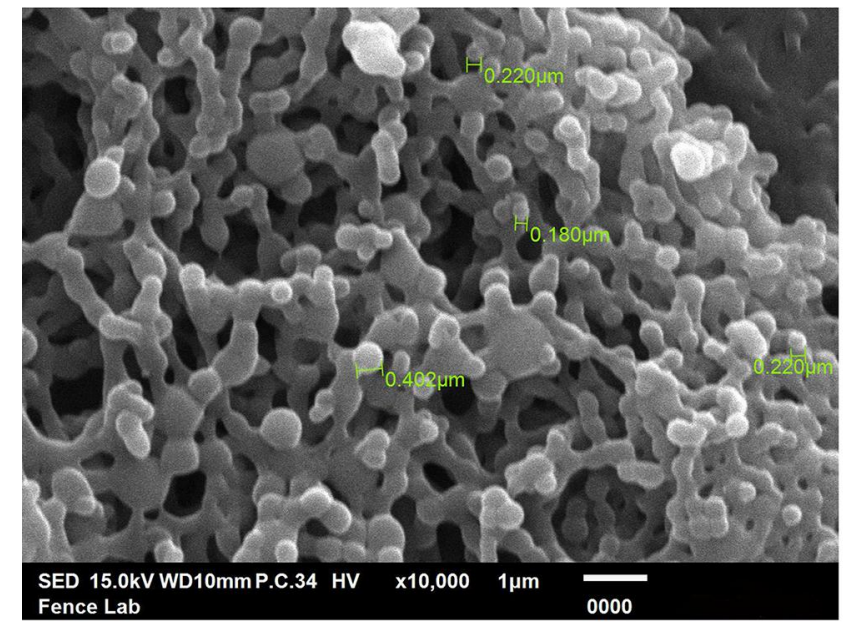

A

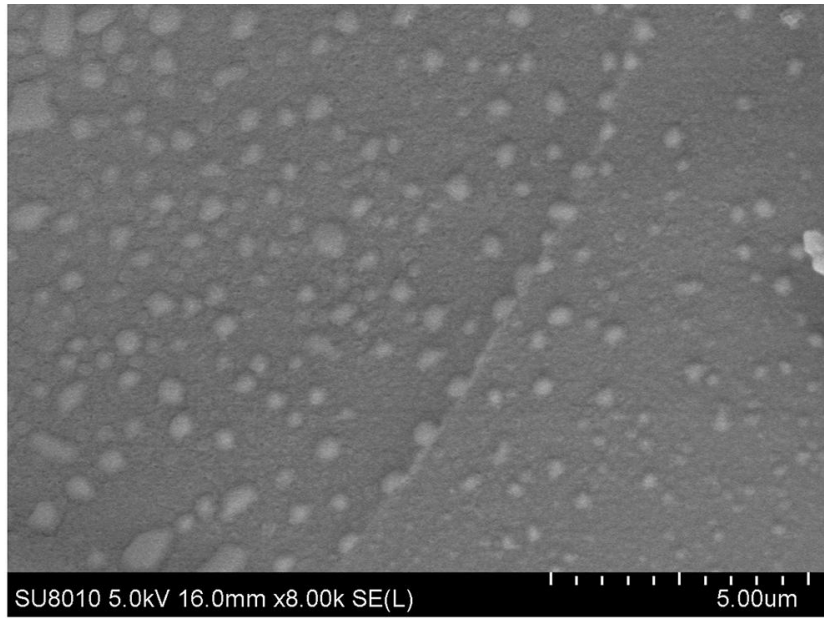

B

Figure I The morphology and size of NPs. Morphology of nanoparticles was observed by a scanning electron microscope at $10,000 \times$ magnification. Notes: (A) The scanning electron microscopy result of rHCA59-PLGA NPs. The scale bar is I $\mu \mathrm{m}$. (B) The scanning electron microscopy result of rHCA59-Chitosan. The scale bar is $5 \mu \mathrm{m}$.

Abbreviations: NPs, nanoparticles; PLGA, poly-D,L-lactide-co-glycolide. 


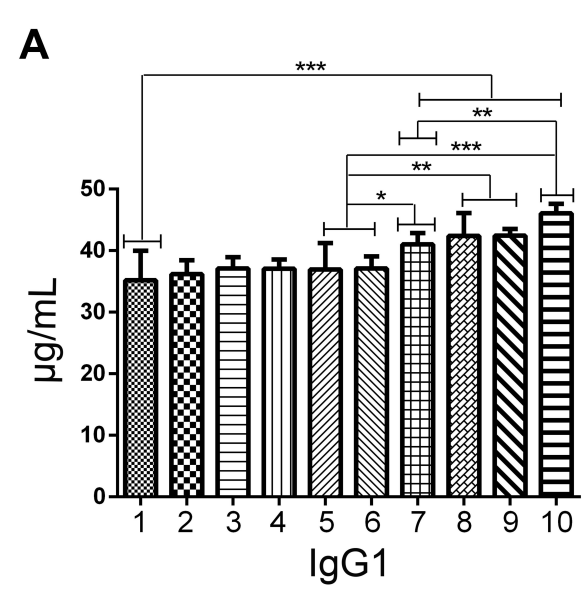

B

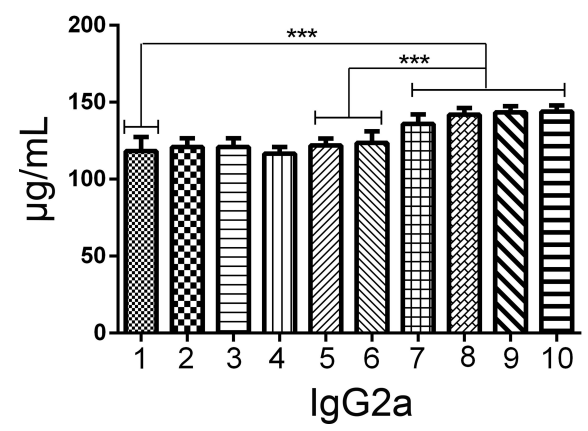

1: PBS

2: PBS-CFA

3: PBS-PLGA

4: PBS-CS

5: $\mathrm{pET}-32 \mathrm{a}$

6: rHCA59

7: rHCA59-CFA

8: rHCA59-CS

9: rHCA59-PLGA

10: rHCA59-CS-PLGA

C

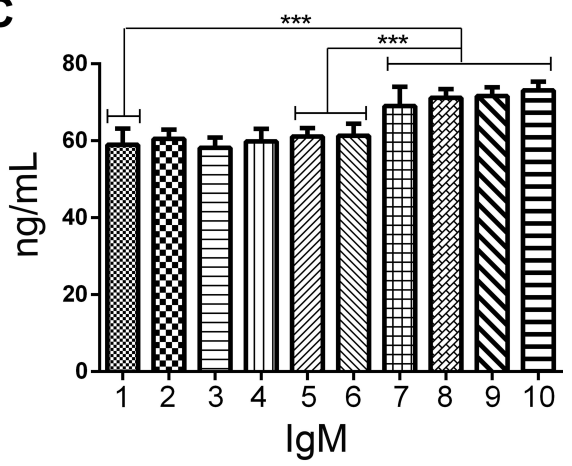

Figure 2 Effects of different antigen delivery systems on the expressions of antibodies. Sera were collected and detected on day I4 by ELISA.

Notes: (I): PBS group (blank control). (2): pET-32a protein group. (3): PBS-PLGA group. (4): PBS-CS group. (5): PBS-CFA group. (6): rHCA59 group. (7): rHCA59-PLGA group. (8): rHCA59-CS group. (9): rHCA59-CFA group. (10): rHCA59-CS-PLGA group. (A) IgGI. (B) IgG2a. (C) IgM. Data are representative of triplicate experiments $(* p<0.05, * * p<0.01$, and $* * * p<0.001)$.

Abbreviations: PLGA, poly-D,L-lactide-co-glycolide; CS, Chitosan; CFA, complete Freund's adjuvant.

respectively). Additionally, the results showed that the level of IgG1 in rHCA59-CS-PLGA group increased significantly when compared with rHCA59-CFA group $(p<0.01)$ (Figure 2A). Mice immunized with rHCA59-CS-PLGA NPs, rHCA59-PLGA NPs, rHCA59-CS NPs, and rHCA59CFA all secreted extremely higher levels of IgG2a and IgM when compared with PBS, rHCA59, and pET-32a protein groups $(p<0.001, p<0.001, p<0.001, p<0.001$, respectively) (Figure 2B and C). In addition, the ratio of IgG2a/ IgG1 in groups rHCA59-PLGA, rHCA59-CS, rHCA59-CSPLGA, and rHCA59-CFA were all above 1 (Table S1).

\section{Cytokine Production}

In this study, the levels of IL-4, IL-12, IL-17, IFN- $\gamma$, and TGF- $\beta$ in mice sera of the ten groups were examined by an ELISA assay. The results showed that mice vaccinated with rHCA59-CS-PLGA NPs, rHCA59-PLGA NPs, rHCA59-CS NPs secreted higher levels of IL-12 when compared with PBS, rHCA59 and pET-32a protein groups ( $p<0.001, p<0.001, p<0.001$, respectively). Mice in
rHCA59-CS-PLGA, rHCA59-PLGA, and rHCA59-CS groups produced higher IL-12 than those in rHCA59CFA group ( $p<0.01, p<0.01, p<0.05$, respectively) (Figure 3A). When compared with PBS group, the levels of IL-17 in rHCA59-CS-PLGA, rHCA59-PLGA, rHCA59-CS, and rHCA59-CFA groups rose obviously ( $p<0.001, p<0.01, p<0.05, p<0.05$, respectively). Additionally, the level of IL-17 in rHCA59-CS-PLGA group also increased significantly when compared with rHCA59-CS and rHCA59-CFA groups ( $p<0.05, p<$ 0.05 , respectively). IL-17 levels were dramatically increased in rHCA59-CS-PLGA and rHCA59-PLGA groups when compared with rHCA59 and pET-32a protein groups ( $p<0.001, p<0.01$, respectively) (Figure 3B).

The enhanced levels of IFN- $\gamma$ were produced in rHCA59-CS-PLGA, rHCA59-CS, and rHCA59-PLGA groups when compared with PBS, rHCA59 and pET-32a protein groups $(p<0.001, p<0.001, p<0.001$, respectively). Furthermore, when compared with rHCA59-CFA group, the levels of IFN- $\gamma$ secreted by rHCA59-CS-PLGA, 
A

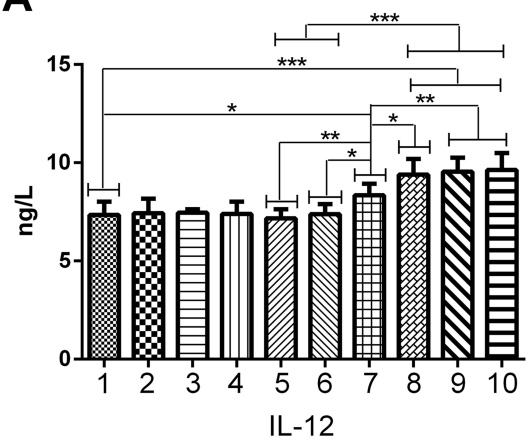

B

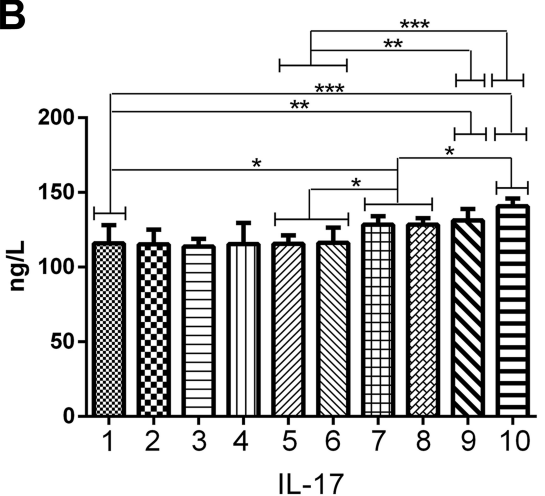

D

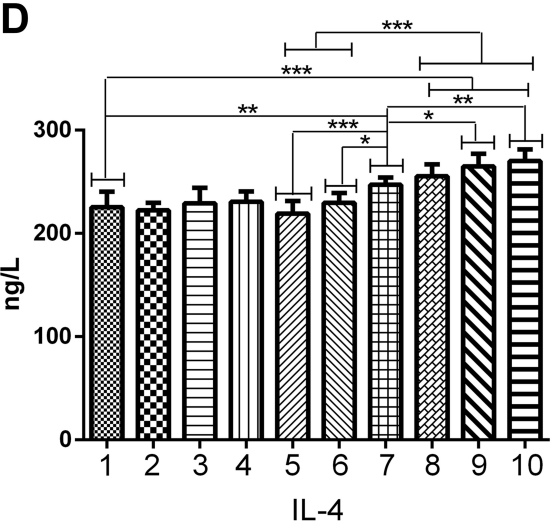

1: PBS

2: PBS-CFA

3: PBS-PLGA

4: PBS-CS

5: $\mathrm{pET}-32 \mathrm{a}$

6: rHCA59

7: rHCA59-CFA

8: rHCA59-CS

9: rHCA59-PLGA

10: rHCA59-CS-PLGA

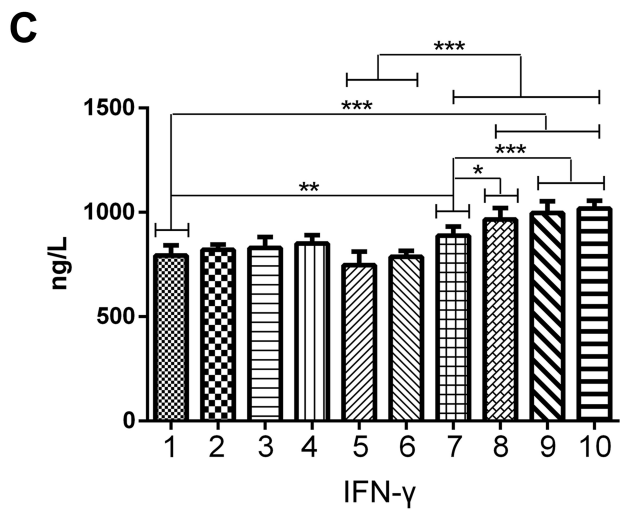

E

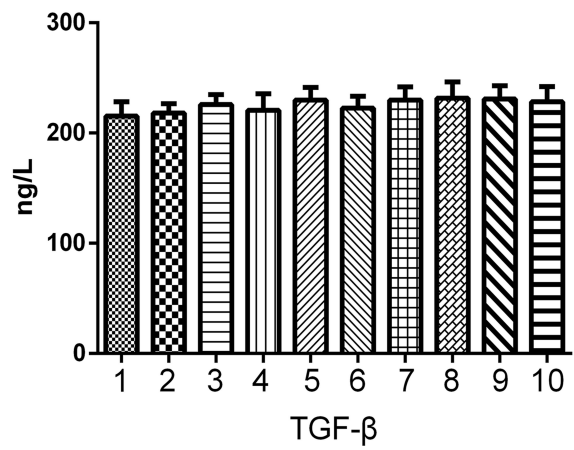

Figure 3 Effects of different antigen delivery systems on the expressions of multiple cytokines. Sera were collected and detected on day I4 by ELISA.

Notes: (I): PBS group (blank control). (2): pET-32a protein group. (3): PBS-PLGA group. (4): PBS-CS group. (5): PBS-CFA group. (6): rHCA59 group. (7): rHCA59-PLGA group. (8): rHCA59-CS group. (9): rHCA59-CFA group. (10): rHCA59-CS-PLGA group. (A) IL-I2. (B) IL-I7. (C) IFN- $\gamma$. (D) IL-4. (E) TGF- $\beta$. Data are representative of triplicate independent experiments $(* p<0.05$, $* * p<0.01$, and $* * * p<0.00 \mathrm{I})$.

Abbreviations: PLGA, poly-D,L-lactide-co-glycolide; CS, Chitosan; CFA, complete Freund's adjuvant; IL, interleukin; ELISA, enzyme linked immunosorbent assay.

rHCA59-PLGA, and rHCA59-CS groups were obviously increased ( $p<0.001, p<0.001, p<0.05$, respectively) (Figure 3C). Higher levels of IL-4 were secreted by the rHCA59-CS-PLGA, rHCA59-PLGA, rHCA59-CS, and rHCA59-CFA groups when compared to that of PBS, rHCA59, and pET-32a protein groups ( $p<0.001, p<$ 0.001, $p<0.001, p<0.01$, respectively). Additionally, the rHCA59-CS-PLGA and rHCA59-PLGA groups produced more IL-4 than rHCA59-CFA group $(p<0.01, p<$ 0.05 , respectively). The rHCA59-CFA group also presented higher IL-4 than rHCA59 and pET-32a protein groups ( $p<0.05, p<0.001$, respectively) (Figure 3D). However, the levels of TGF- $\beta$ among all groups did not show apparent fluctuations $(p=0.083)$ (Figure 3E). 


\section{Lymphocyte Proliferation Induced by rHCA59-PLGA NPs, rHCA59-CS NPs, and $\mathrm{rHCA59-CS-PLGA} \mathrm{NPs}$}

Mice spleen lymphocytes were isolated from different groups in the second week post immunization and their proliferative responses specific to rHCA59 were investigated and expressed as SI values. The SI values in positive control (ConA) and rHCA59-CS-PLGA groups were the highest when compared with PBS, rHCA59, and pET-32a protein groups $(p<0.001, p<0.001, p<0.001$, respectively). Furthermore, the rHCA59-PLGA and rHCA59-CS groups also showed higher SI values than those in PBS, rHCA59, and pET-32a protein groups ( $p<0.05, p<0.05$, $p<0.05$, respectively). When compared with rHCA59CFA group, the positive control and rHCA59-CS-PLGA groups presented obvious enhancement, referring to the SI values ( $p<0.001, p<0.01$, respectively) (Figure 4).

\section{The Activation of T Cells}

The percentages of $\mathrm{CD}^{+}$and $\mathrm{CD} 8^{+} \mathrm{T}$ cells in each group were examined by flow cytometry. As shown in Figure 5, when compared with PBS group, the rHCA59-PLGA, rHCA59-CS-PLGA, rHCA59-CS, and rHCA59-CFA groups showed significantly higher proportions of $\mathrm{CD} 3 \mathrm{e}^{+} \mathrm{CD} 4^{+}$ cells ( $p<0.001, p<0.001, p<0.001, p<0.01$, respectively). In comparison to the rHCA59-CFA and rHCA59-CS groups, the rHCA59-CS-PLGA group generated a higher percentage of $\mathrm{CD}_{\mathrm{e}} \mathrm{e}^{+} \mathrm{CD}^{+}$cells $(p<0.01, p<0.05$, respectively). Additionally, the percentages of $\mathrm{CD}^{+} \mathrm{e}^{+} \mathrm{CD} 4^{+}$cells in rHCA59-CS-PLGA, rHCA59-PLGA, rHCA59-CS, and rHCA59-CFA groups were significantly higher than those in rHCA59 and pET-32a protein groups $(p<0.001, p<$ $0.001, p<0.01, p<0.05$, respectively) (Figure 5C).

The elevated percentages of $\mathrm{CD} 3 \mathrm{e}^{+} \mathrm{CD} 8^{+}$cells were obtained in rHCA59-CS-PLGA, rHCA59-CS, rHCA59PLGA, and rHCA59-CFA groups when compared with PBS and pET-32a protein groups $(p<0.001, p<0.001$, $p<0.001, p<0.001$, respectively). Additionally, the rHCA59-CS-PLGA, rHCA59-PLGA, and rHCA59-CS groups also generated an obvious increase in $\mathrm{CD} 3 \mathrm{e}^{+}$ $\mathrm{CD}^{+}$cells in comparison to rHCA59-CFA group $(p<$ $0.001, p<0.001, p<0.05$, respectively). In comparison with rHCA59-CS group, the percentages of $\mathrm{CD} 3 \mathrm{e}^{+} \mathrm{CD} 8^{+}$ $\mathrm{T}$ cells were significantly upregulated in rHCA59-CSPLGA and rHCA59-PLGA groups ( $p<0.001, p<0.01$, respectively) (Figure 5D).

\section{Evaluation of the Effects of the Four Delivery Systems on DC Phenotype}

The expressions of CD83 and CD86 on DCs were investigated in the ten groups (Figure 6). Mice vaccinated with rHCA59-CS-PLGA NPs, rHCA59-PLGA NPs, rHCA59CS NPs, and rHCA59-CFA all produced greatly enhancements in the percentages of $\mathrm{CD} 11 \mathrm{c}^{+} \mathrm{CD} 83^{+}$and $\mathrm{CD} 11 \mathrm{c}^{+}$ $\mathrm{CD}^{2} 6^{+}$when compared with PBS, rHCA59, and pET-32a protein groups $(p<0.001, p<0.001, p<0.001, p<0.001$, respectively). Additionally, in comparison to rHCA59CFA group, the percentages of $\mathrm{CD} 11 \mathrm{c}^{+} \mathrm{CD} 83^{+}$and

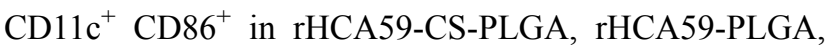
and rHCA59-CS groups increased significantly $(p<$ $0.001, p<0.001, p<0.001$, respectively). When compared with rHCA59-CS and rHCA59-PLGA groups, the rHCA59-CS-PLGA group also showed a noticeable enhancement in the percentage of $\mathrm{CD}_{11 \mathrm{c}^{+}} \mathrm{CD}^{+} 3^{+}(p<$ $0.001)$. What is more, the percentages of $\mathrm{CD} 11 \mathrm{c}^{+} \mathrm{CD} 86^{+}$ cells in rHCA59-CS-PLGA group were higher than those in rHCA59-CS group $(p<0.01)$.

\section{Discussion}

The protein HCA59 of HcESPs had been identified to bind to the PBMCs of goats at larval stages 4 and 5 of the nematode in vitro, ${ }^{36}$ which indicated that HCA59 of $H$. contortus might partake in the interactions between the nematode and the host, as well as might adjust host immune responses against infection with the parasite. Chitosan is a natural polymer generated by deacetylation of chitin, which is one of the most plentiful polysaccharides in nature. Its biodegradable, biocompatible, mucoadhesive, and immunomodulatory properties make it hold the potential to be a fascinating excipient for vaccine and drug-vaccine delivery. ${ }^{37,38}$ It had also been identified that antigen loaded PLGA could induce cell-mediated immune responses and enhance lymphocyte proliferation, owing to its slow-release properties and the depot formation of the antigen. ${ }^{39-41}$ These properties suggested that PLGA and Chitosan might act as better adjuvants to elicit immune responses. In the present study, the immune enhancement effects of PLGA and Chitosan nanoparticles as antigen delivery systems on rHCA59 in mice were detected and compared with the CFA antigen delivery system for the first time in vivo.

The productivity and encapsulation efficiency of PLGA NPs are particularly significant for loading valued protein antigens. ${ }^{42}$ Some formulation parameters, such as the 


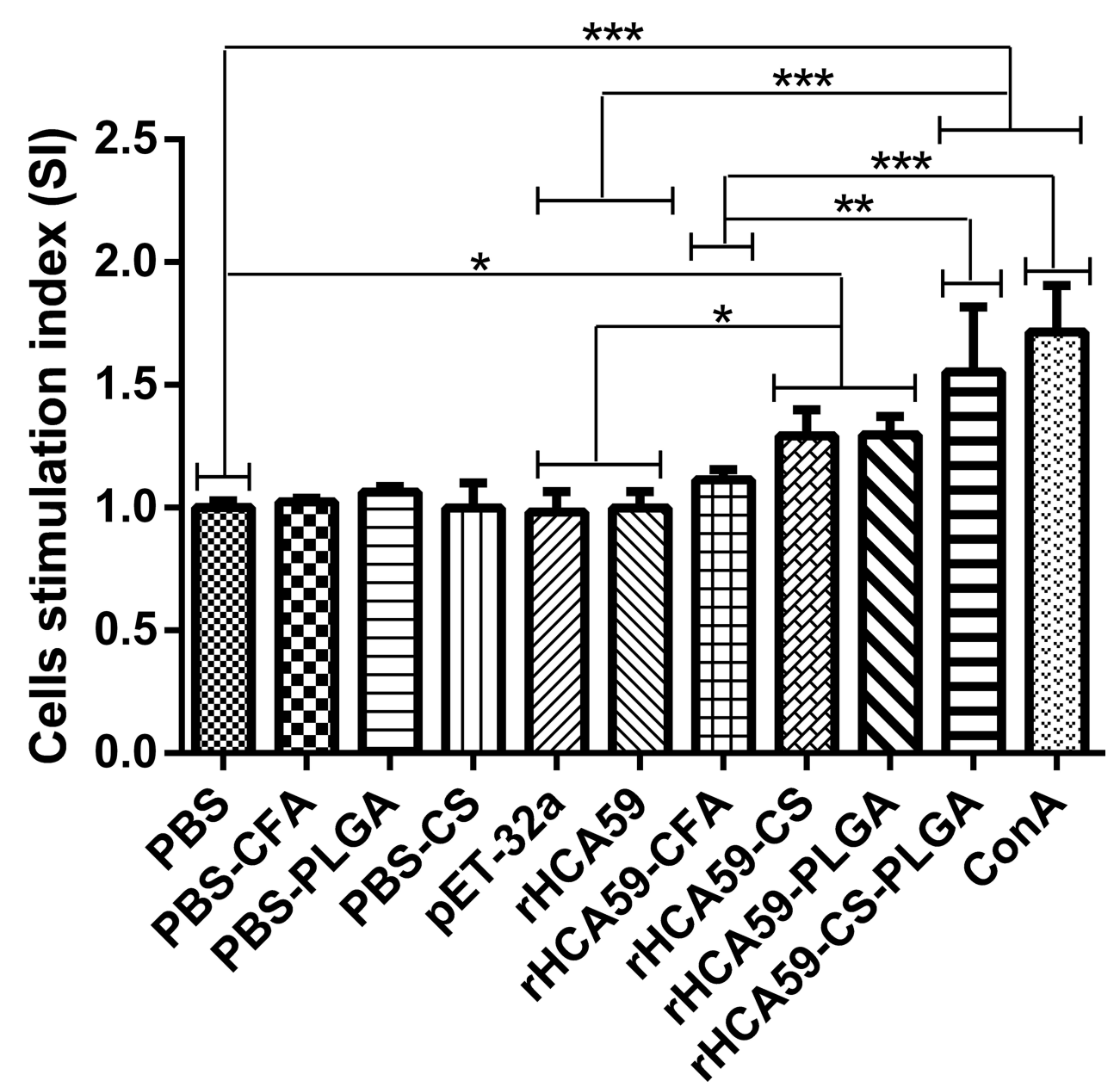

Figure 4 Evaluation of the activation of rHCA59-specific lymphocytes in different antigen delivery systems. Spleen lymphocytes were isolated from the ten groups in the second week after immunization and their proliferative responses specific to rHCA59 were investigated using a CCK-8 kit.

Notes: Proliferative responses of rHCA59-specific lymphocytes were expressed as $\mathrm{SI}$ values. Data are representative of three independent experiments and the values presented here are the means \pm SEM $(* p<0.05$, $* * p<0.01$, and $* * * p<0.001)$.

Abbreviations: NPs, nanoparticles; SI, stimulation index.

phase ratio and PVA concentration, affected the yield and encapsulation efficiency of the final nanoparticles, when the double emulsion solvent evaporation method was applied. ${ }^{43}$ In the current study, the detection of PVA concentration demonstrated that 6\% PVA was more suitable for the production of PLGA NPs. Under the concentration of $6 \%$ PVA, a high encapsulation efficiency of the final PLGA particles was obtained (89\%). The high encapsulation efficiency and the size of rHCA59-PLGA NPs (180 nm-402 nm) and rHCA59-CS NPs (200 nm-500 nm) (Figure 1) confirmed that the rHCA59-PLGA NPs and the rHCA59-CS NPs possessed appropriate physicochemical characteristics, which were comparable to the reported nanovaccines. ${ }^{44}$

During the process of immune responses, cytokine played important roles. ${ }^{45}$ IFN- $\gamma$ was secreted by Th1 lymphocytes and was related to cellular immune responses. ${ }^{46}$
IL-12 was an important effector and was one of the key players in the DC-T cell cross-talk. ${ }^{15}$ Previous studies showed that high IL-12 level could elicit the secretion of IFN- $\gamma$ by $\mathrm{T}$ cells and trigger cytotoxic $\mathrm{T}$ lymphocytes and Th1 cell differentiation. ${ }^{47}$ In the present study, the levels of IL-12 and IFN- $\gamma$ were significantly enhanced in the rHCA59-CS-PLGA, rHCA59-PLGA, rHCA59-CS, and rHCA59-CFA groups, especially in rHCA59-CS-PLGA group, when compared with PBS, rHCA59 and pET-32a protein groups (Figure $3 \mathrm{~A}$ and $\mathrm{C}$ ). These findings suggested that rHCA59 might have the ability to activate the process of DC-T cell cross-talk and the differentiation of Th1 cells. Recently, Th17 cells were found to play significant roles in eliminating pathogens during host defense responses. ${ }^{42}$ As shown in Figure 3B, the highest levels of IL-17 were produced by rHCA59-CS-PLGA and rHCA59PLGA groups, followed by rHCA59-CS and rHCA59- 

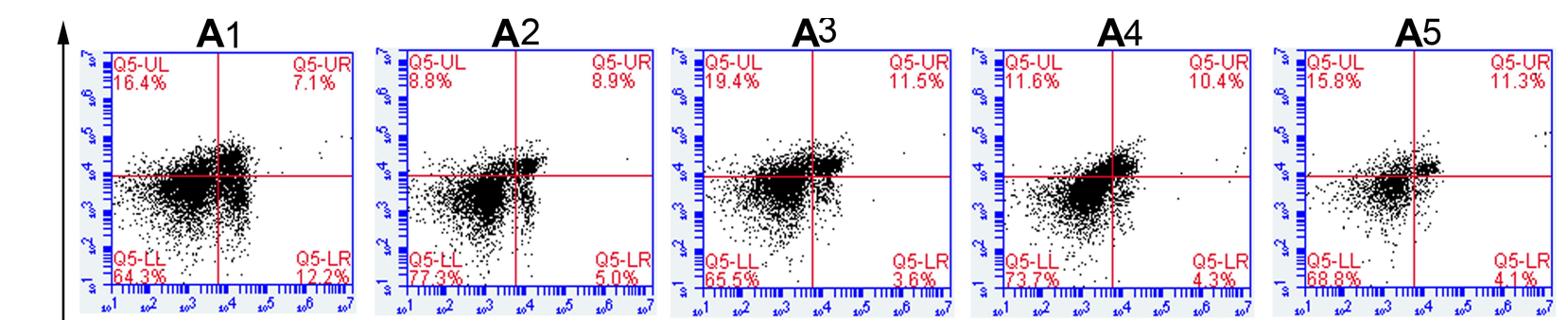

A6

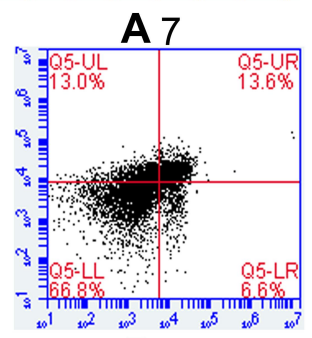

A 8

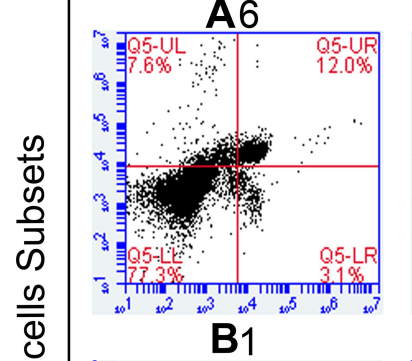

B 2

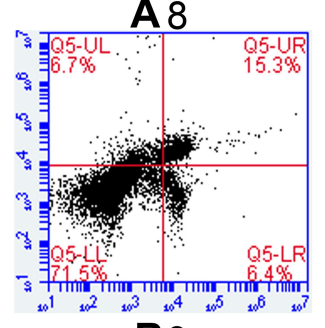

A9

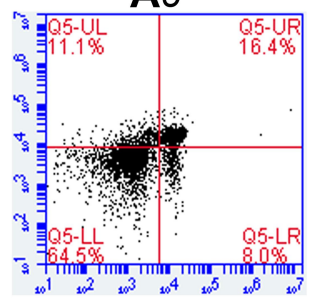

B4
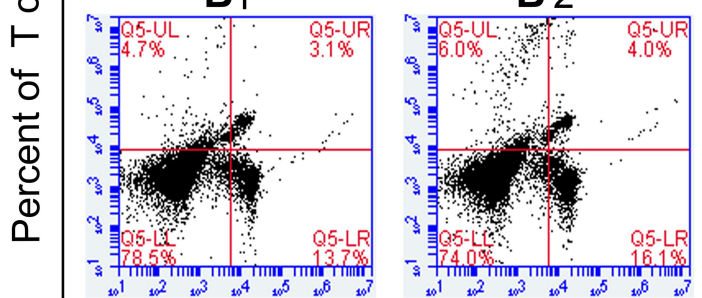

B3
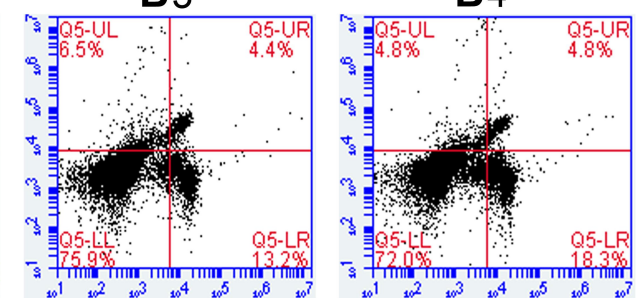

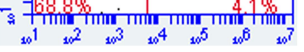

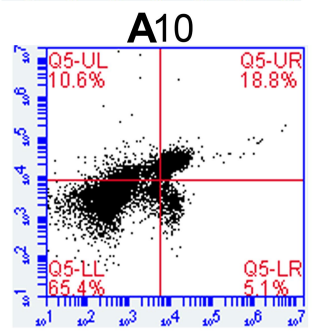

B6

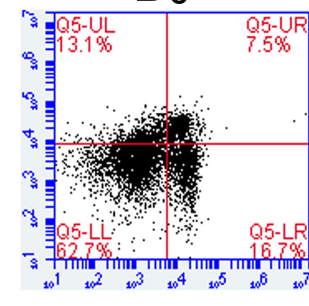

B7

B8
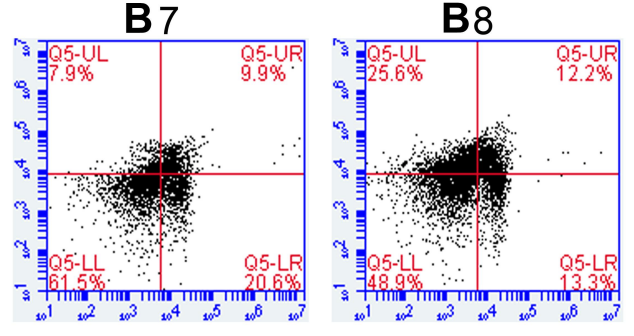

B9
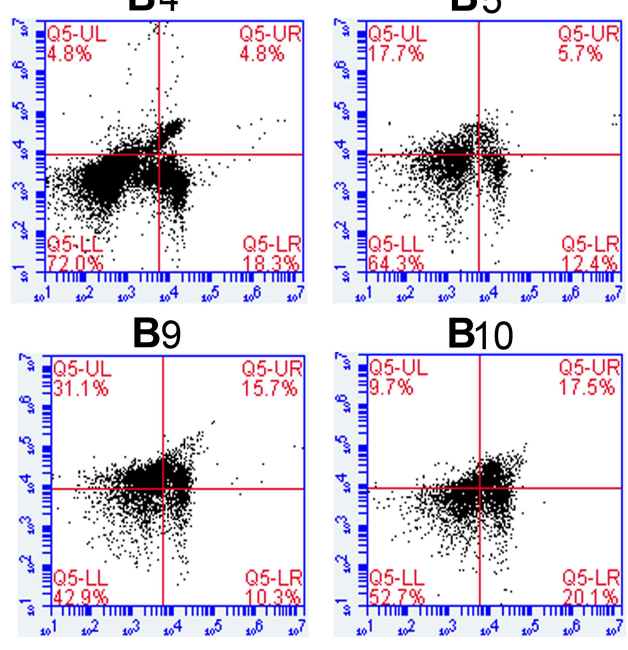

\section{Groups}
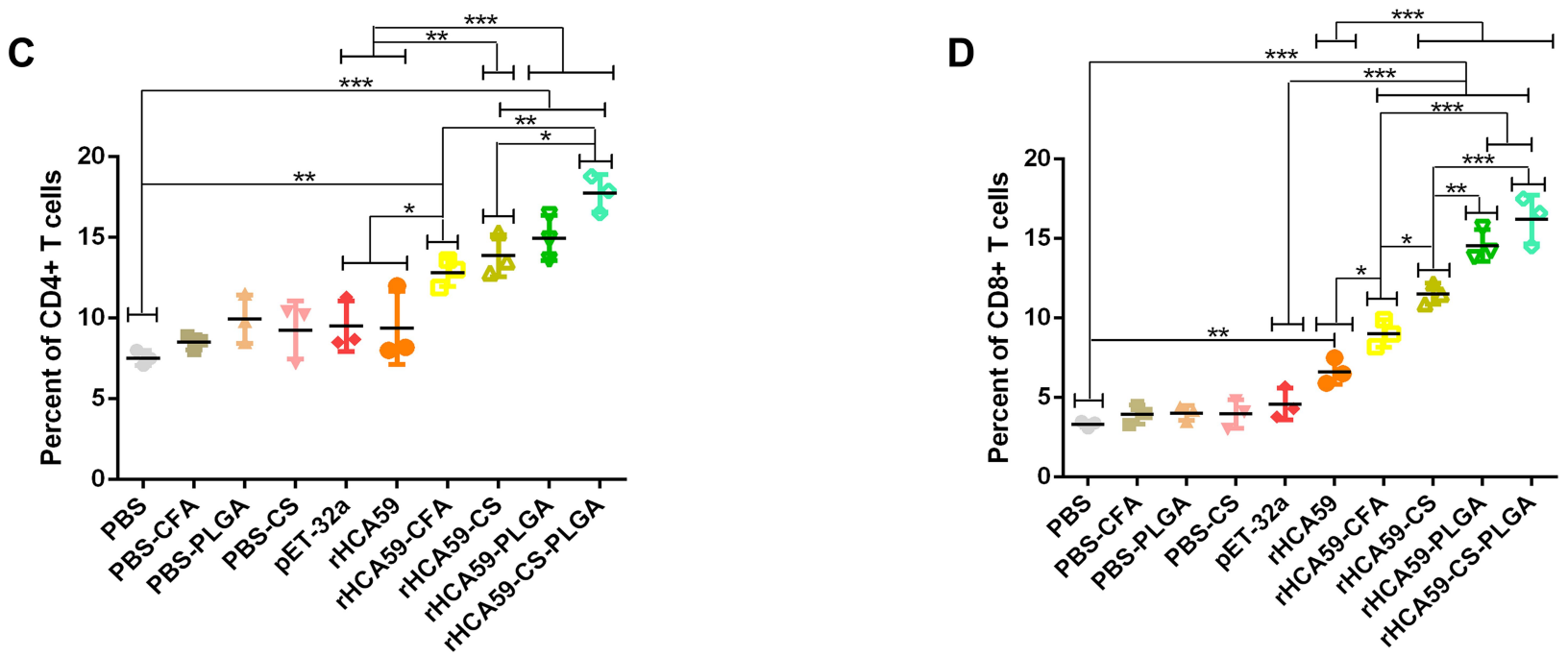

Figure 5 Effects of different antigen delivery systems on T lymphocyte subsets.

Notes: rHCA59 loaded nanoparticles could affect the proportions of CD4 ${ }^{+} \mathrm{T}$ cells and CD8 ${ }^{+} \mathrm{T}$ cells in immunized mice. The percentages of CD4 ${ }^{+} \mathrm{T}$ cells $\left(\mathbf{A l}-\mathbf{A}\right.$ I0) and CD8 ${ }^{+} \mathrm{T}$ cells (B I-B I 0) in ten groups were investigated by flow cytometry on day 14 after immunization. (C and D) Different treatments affected the proportions of CD4 ${ }^{+}$T cells and CD8 ${ }^{+} \mathrm{T}_{\text {cells. }}$ (AI and BI) PBS group (blank control). (A2 and B2) PBS-CFA group. (A3 and B3) PBS-PLGA group. (A4 and B4) PBS-CS group. (A5 and B5) pET-32a protein group. (A6 and B6) rHCA59 group. (A7 and B7) rHCA59-CFA group. (A8 and B8) rHCA59-CS group. (A9 and B9) rHCA59-PLGA group. (A10 and B I0) rHCA59-CS-PLGA group. The results shown here are from three independent experiments $(* p<0.05$, ** $p<0.01$, and $* * * p<0.001)$.

Abbreviations: CD4, cluster of differentiation 4; CD8, cluster of differentiation 8; T cells, thymus cells; PLGA, poly-D,L-lactide-co-glycolide; CS, Chitosan; CFA, complete Freund's adjuvant. 

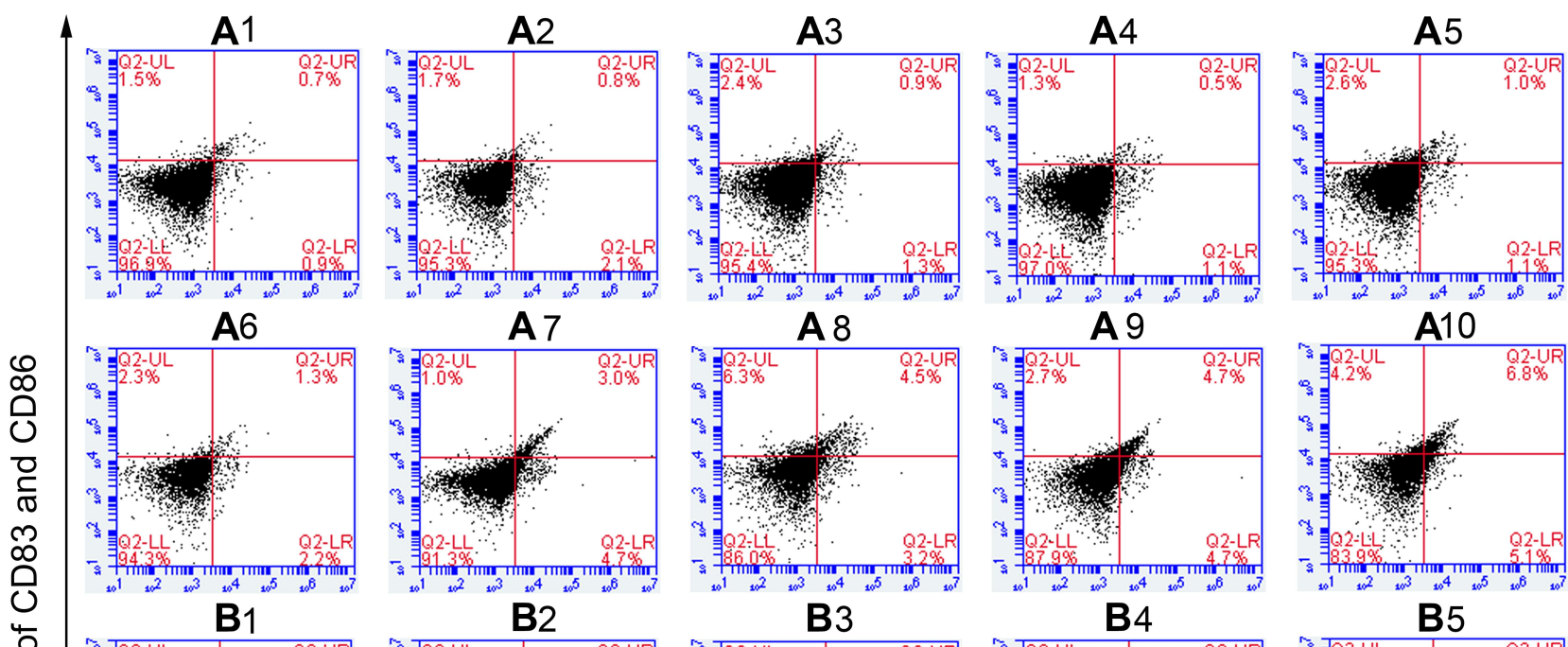

B2

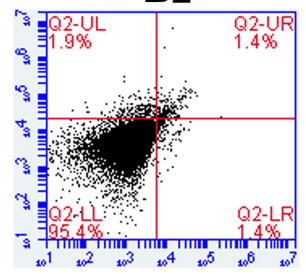

B7

B6
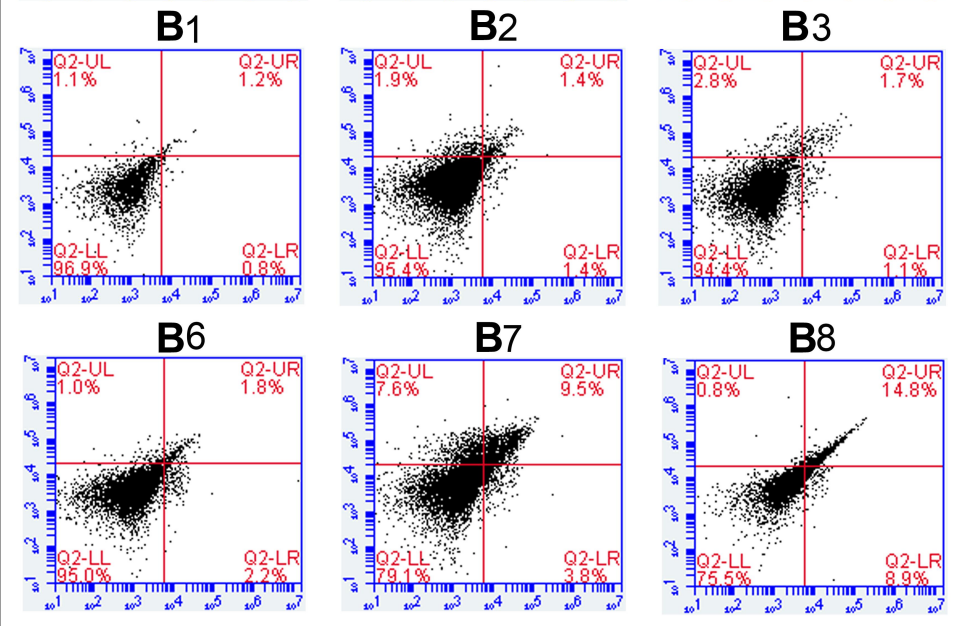

B8
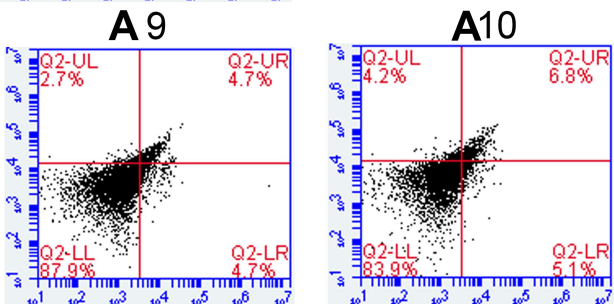

B4

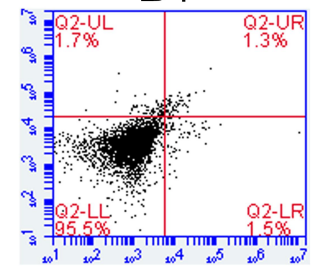

B9
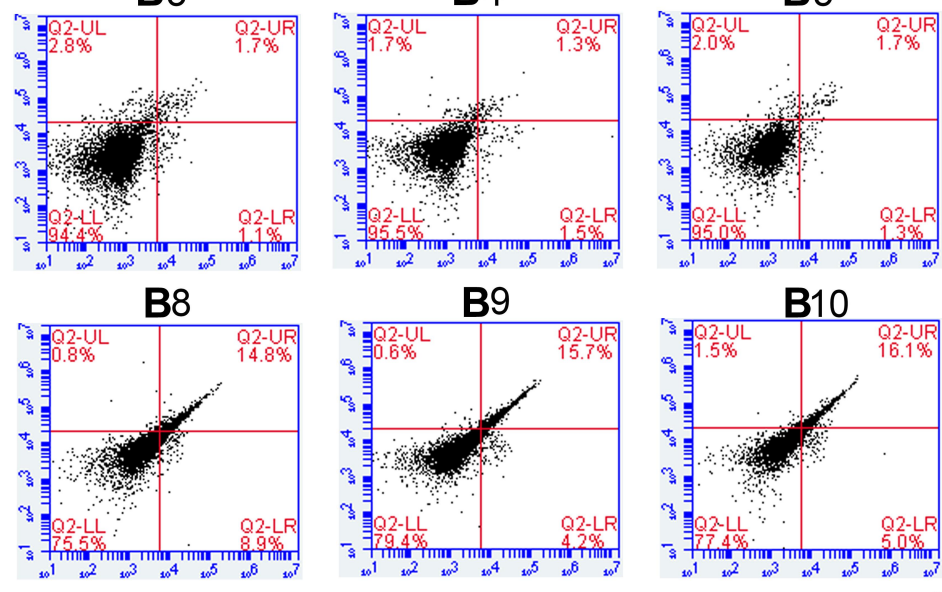

B10

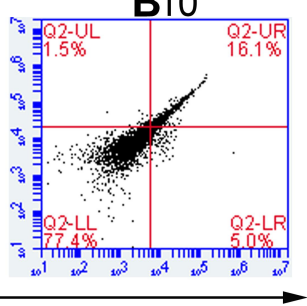

Groups

C

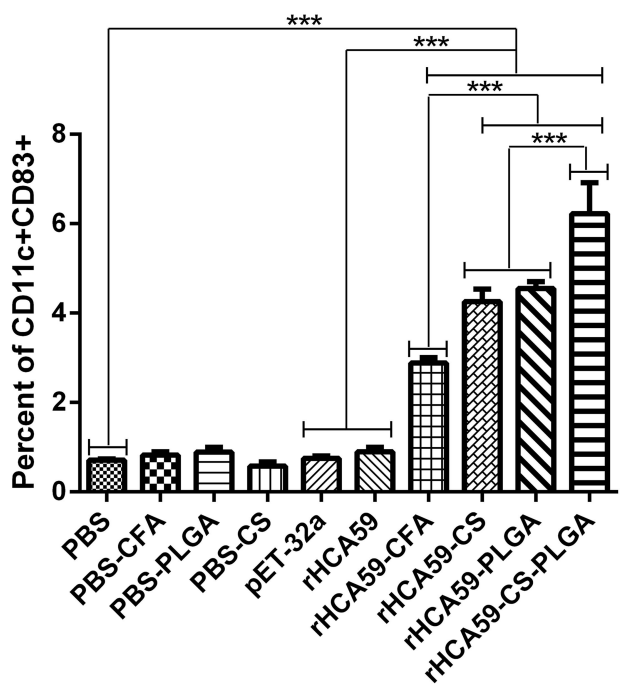

D

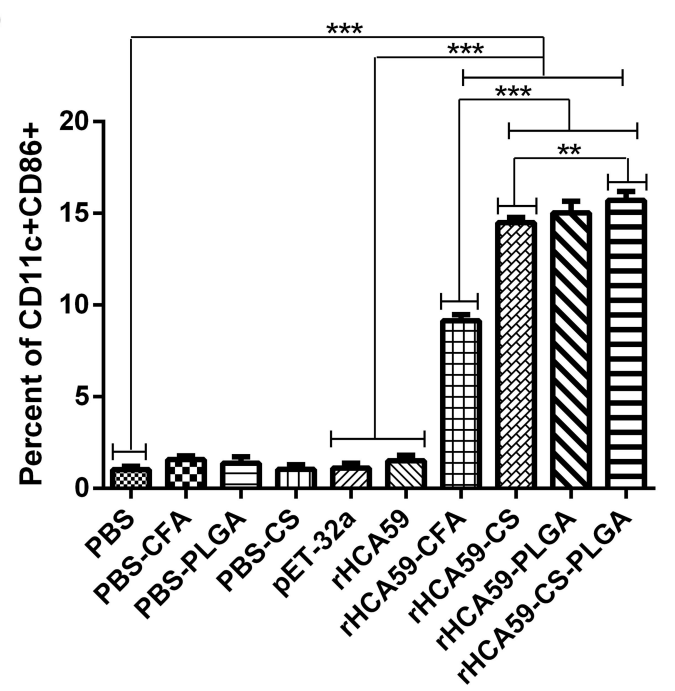

Figure 6 Effects of different antigen delivery systems on the spleen dendritic cell maturation.

Notes: The expressions of CD83 (AI-A I0) and CD86 (BI-B I0) on DCs were examined by flow cytometry on day I4 after immunization. (C and D) Different treatments affected the percentages of $\mathrm{CDIIC}{ }^{+} \mathrm{CD}_{3}{ }^{+}$and $\mathrm{CDIIC}{ }^{+} \mathrm{CD}_{6}{ }^{+}$. (AI and BI) PBS group (blank control). (A2 and B2) pET-32a protein group. (A3 and B3) PBS-CFA group. (A4 and B4) PBS-CS group. (A5 and B5) PBS-PLGA group. (A6 and B6) rHCA59 group. (A7 and B7) rHCA59-CFA group. (A8 and B8) rHCA59-CS group. (A9 and B9) rHCA59-PLGA group. (A10 and B 10) rHCA59-CS-PLGA group. Data are presented as the mean \pm SEM and representative of triplicate experiments $(* * p<0.01$, and $* * * p<0.001)$.

Abbreviations: CD83, cluster of differentiation 83; CD86, cluster of differentiation 86; DCs, dendritic cells; SEM, mean \pm the standard error of mean. 
CFA groups, which indicated that rHCA59 could induce Th17 response and might participate in the protection against the infection of $H$. contortus.

IL-4 was a cytokine mainly secreted by Th2 cells and could elicit the proliferation and differentiation of B cells to generate antibodies, promote the differentiation of $\mathrm{CD} 4^{+} \mathrm{T}$ cells into $\mathrm{Th} 2$ cells, and increase the activities of macrophages. ${ }^{48}$ TGF- $\beta$ was a member of the TGF- $\beta$ superfamily and could restrain the secretion of IgM by BCDFdependent B cells, and the secretion of TNF- $\alpha$ as well as IFN- $\gamma$ by PBMCs. In the current study, the level of TGF- $\beta$ did not increase obviously, while the levels of IL-4 secreted by rHCA59-CS-PLGA, rHCA59-PLGA, rHCA59-CS, and rHCA59-CFA groups increased significantly (Figure 3D and E), especially in the rHCA59-CSPLGA group, which indicated that the antigen delivery systems could induce the generation of Th2 cells. In mice, Th1 type cells induced the production of the $\operatorname{IgG} 2 \mathrm{a}$ antibody and Th2 cells induced the production of the IgG1 antibody. The index of IgG2a/IgG1 above 1 meant a shift of the immune response toward the Th1 type, whereas the value of index below 1 meant a shift of the immune response toward the Th2 type. ${ }^{49}$ In this study, the values of index in rHCA59-CS-PLGA, rHCA59-PLGA, rHCA59-CS and rHCA59-CFA groups were all above 1 (Table S1). These findings suggested that all of the four antigen delivery systems tended to induce Th1 type immune responses, though they were able to elicit humoral response.

The proliferation of lymphocytes was the most significant index embodying organic immunity in vivo. ${ }^{32}$ In the current study, the proliferations of lymphocytes in all groups were tested. The results showed that when compared with PBS, rHCA59 and pET-32a protein groups, the proliferation abilities of lymphocytes from rHCA59-CSPLGA, rHCA59-PLGA and rHCA59-CS groups were obviously enhanced, especially from the rHCA59-CSPLGA group (Figure 4). These findings demonstrated that the rHCA59-CS-PLGA antigen delivery system was the most effective approach to stimulate the proliferation of lymphocytes in all referred groups.

The CD8 receptor was generally expressed on cytotoxic T lymphocytes, while the CD4 receptor belonging to the co-receptor of the TCR was primarily expressed on Th-cells. ${ }^{50}$ Generally, the $\mathrm{CD}^{+} \mathrm{T}$ cells functioned to wreck infected host cells and the $\mathrm{CD} 4^{+} \mathrm{T}$ cells regulated the immune responses, including cell-mediated response and humoral response. ${ }^{51,52}$ In this study, after the mice were injected with rHCA59-CS-PLGA NPs, rHCA59PLGA NPs, rHCA59-CS NPs, and rHCA59-CFA, both T-cell subsets were increased when compared with PBS, rHCA59 and pET-32a protein groups, especially in the rHCA59-CS-PLGA group (Figure 5). These findings revealed that the rHCA59-CS-PLGA antigen delivery system was the most effective way to induce the $\mathrm{CD} 4^{+}$and $\mathrm{CD}^{+} \mathrm{T}$ cells responses.

DCs were the most powerful APCs with the abilities to induce the primary immune responses and to start the adaptive immune responses. ${ }^{53}$ In mouse, almost all the DC subsets expressed the typical surface marker CD11C. ${ }^{54} \mathrm{CD} 83$ was a prominent surface marker expressed in mature murine DCs and the other cells and functioned as an important immune checkpoint. ${ }^{55}$ Another costimulatory molecule (CD86) expressed by DCs was required for DCs functions to activate $\mathrm{T}$ cells and induce the adaptive immunity effectively. ${ }^{56}$ In the current study, the expressions of CD83 and CD86 on DCs were detected. As shown in Figure 6, the percentages of $\mathrm{CD}_{11 \mathrm{C}^{+}} \mathrm{CD}^{+} 3^{+}$and $\mathrm{CD} 11 \mathrm{C}^{+} \mathrm{CD}^{+} 6^{+}$cells were significantly increased in mice injected with rHCA59CS-PLGA NPs, rHCA59-PLGA NPs, rHCA59-CS NPs, and rHCA59-CFA when compared with the mice immunized with rHCA59 and pET-32a proteins. The rHCA59-CSPLGA group also presented an obvious enhancement in the percentages of $\mathrm{CD}_{11 \mathrm{C}^{+}} \mathrm{CD} 3^{+}$and $\mathrm{CD} 11 \mathrm{C}^{+} \mathrm{CD}^{+} 6^{+}$ cells in comparison with rHCA59-CS NPs and rHCA59CFA groups (Figure 6). These findings suggested that the vaccines could prompt the maturation of DCs and improve their functions, especially for the rHCA59-CS-PLGA antigen delivery system.

The protection induced by vaccine concerns the activations of innate and adaptive responses. ${ }^{57}$ Generally, the innate response was generated at 1-3 days post vaccination and proceeded to the 7 days. The adaptive response started at the 7 days post vaccination and lasted for different times that depended on the types of vaccines and pathogens. The adaptive response played a more significant role than the innate response in the protection. In the current research, the immune parameters, including antibodies, main cytokines, T cell types, and percentages of DC subsets, were examined at the 14 days post immunization with vaccines to ensure the observations of the diverse abilities of different vaccinations to induce adaptive response. However, the productions of some cytokines, including IL- 2 and TNF- $\alpha$, and the T cells in the gut were not investigated at the check point. The changes of the parameters at the time before the check point were also not observed. They need further investigations. 
The PLGA and CS carriers are most frequently used in the delivery systems for drug and vaccines. ${ }^{58,59}$ It was found that the incorporation of CS into PLGA could overcome some obstacles of PLGA, such as release profile and instability of antigen during encapsulation procedure and storage, ${ }^{58}$ and enhance the delivery effects in both drugs and vaccines. ${ }^{60-64}$ The mechanisms of the synergistic effects at least included the enhancements of its stability, cellular uptake, targeting capabilities, and drug or antigen release regulation through $\mathrm{CS} \mathrm{pH}-$ triggered ability. ${ }^{65,66}$ In the current study, the rHCA59CS-PLGA group containing equal of $10 \mu \mathrm{g}$ rHCA59-CS NPs and $10 \mu \mathrm{g}$ rHCA59-PLGA NPs also displayed synergistic action and induced stronger immune responses than other groups. The mechanism might be the same to the incorporation of CS into PLGA. However, it should be further probed.

\section{Conclusion}

This study showed that HCA59 was an essential and active protein in HcESPs. Using the rHCA59-CS-PLGA antigen delivery system, it could significantly increase the levels of antibodies (IgG1, IgG2a, IgM) and cytokines (IL-4, IL-17, IL-12, and IFN- $\gamma$ ), could better promote the differentiation $\left(\mathrm{CD}^{+} \mathrm{CD}^{+}, \mathrm{CD}^{+} \mathrm{CD}^{+}\right)$and proliferation of lymphocytes (SI), as well as maturation of $\mathrm{DCs}\left(\mathrm{CD} 11 \mathrm{C}^{+} \mathrm{CD} 83^{+}\right.$,

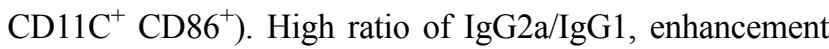
of IL-4, IL-12, and IFN- $\gamma$, as well as the promoted maturation of DCs indicated that rHCA59-CS-PLGA delivery system was biased to elicit Th1 type immune response, though it was able to induce humoral response. The increased IL-17 indicated that HCA59 could elicit Th17 response in the protection against $H$. contortus infection.

These findings will not only help to better comprehend the functions of HCA59 but contribute to the applications of bioactive polymers as antigen delivery adjuvants in animal vaccines. For the nematode $H$. contortus mainly infect the ruminants, the efficiency of the nanovaccine rHCA59-CS-PLGA should be further investigated in the natural host of the parasite.

\section{Data Sharing Statement}

Data supporting this article are shown in Figures 1-6 and its Supplementary Materials. The data sets analyzed in the present study are available from the corresponding authors upon reasonable request.

\section{Ethics Approval and Informed Consent}

The animal experiments in this study were handled according to the guidelines of the Animal Ethics Committee, Nanjing Agricultural University, China. All experimental protocols were approved by the Science and Technology Agency of Jiangsu Province (The approval ID is SYXK (SU) 2010-0005).

\section{Acknowledgments}

We are grateful for the constructive comments about this manuscript to Prof. Roger Prichard from the Institute of Parasitology, McGill University.

\section{Funding}

This research was funded by the National Key Research and Development Program of China under Grant (No. 2017YFD0501200) and the National Key Basic Research Program (973 Program) of P.R. China under Grant (No. 2015CB150300).

\section{Disclosure}

The authors report no conflicts of interest in this work.

\section{References}

1. Emery DL, Hunt PW, Le Jambre LF. Haemonchus contortus: the then and now, and where to from here? Int J Parasitol. 2016;46 (12):755-769. doi:10.1016/j.ijpara.2016.07.001

2. Saddiqi HA, Jabbar A, Sarwar M, et al. Small ruminant resistance against gastrointestinal nematodes: a case of Haemonchus contortus. Parasitol Res. 2011;109(6):1483-1500. doi:10.1007/s00436-0112576-0

3. Rathore DK, Suchitra S, Saini M, Singh BP, Joshi P. Identification of a $66 \mathrm{kDa}$ Haemonchus contortus excretory/secretory antigen that inhibits host monocytes. Vet Parasitol. 2006;138(3-4):291-300. doi:10.1016/j.vetpar.2006.01.055

4. Schallig HD, van Leeuwen MA, Cornelissen AW. Protective immunity induced by vaccination with two Haemonchus contortus excretory secretory proteins in sheep. Parasite Immunol. 1997;19(10):447-453. doi:10.1046/j.1365-3024.1997.d01-148.x

5. Cox GN, Pratt D, Hageman R, Boisvenue RJ. Molecular-cloning and primary sequence of a cysteine protease expressed by Haemonchus-contortus adult worms. Mol Biochem Parasit. 1990;41 (1):25-34. doi:10.1016/0166-6851(90)90093-2

6. Knox DP. Development of vaccines against gastrointestinal nematodes. Parasitology. 2000;120:S43-S61. doi:10.1017/ S0031182099005764

7. Sun YM, Yan RF, Muleke CI, Zhao GW, Xu LX, Li XR. Recombinant galectins of Haemonchus contortus parasite induces apoptosis in the peripheral blood lymphocytes of goat. Int J Pept Res Ther. 2007;13 (3):387-392. doi:10.1007/s10989-006-9045-0

8. Yatsuda AP, Krijgsveld J, Cornelissen AWCA, Heck AJR, de Vries E. Comprehensive analysis of the secreted proteins of the parasite Haemonchus contortus reveals extensive sequence variation and differential immune recognition. $J$ Biol Chem. 2003;278 (19):16941-16951. doi:10.1074/jbc.M212453200 
9. Aimulajiang K, Wen Z, Tian X, et al. Unveiling the immunomodulatory characteristics of Haemonchus contortus ephrin domain containing protein in the parasite-host interactions. Animals (Basel). 2020;10(11).

10. Wang Y, Han KJ, Pang XW, et al. Large scale identification of human hepatocellular carcinoma-associated antigens by autoantibodies. J Immunol. 2002;169(2):1102-1109. doi:10.4049/jimmunol.169.2. 1102

11. Li B, Wang Y, Chen J, Wu H, Chen W. Identification of a new HLAA*0201-restricted CD8+ T cell epitope from hepatocellular carcinoma-associated antigen HCA587. Clin Exp Immunol. 2005;140 (2):310-319. doi:10.1111/j.1365-2249.2005.02786.X

12. Ehsan M, Hu RS, Liang QL, et al. Advances in the development of anti-Haemonchus contortus vaccines: challenges, opportunities, and perspectives. Vaccines (Basel). 2020;8(3).

13. Yang $\mathrm{R}, \mathrm{Xu} \mathrm{J}, \mathrm{Xu} \mathrm{L}$, et al. Cancer cell membrane-coated adjuvant nanoparticles with mannose modification for effective anticancer vaccination. ACS Nano. 2018;12(6):5121-5129. doi:10.1021/ acsnano.7b09041

14. Wieber A, Selzer T, Kreuter J. Characterisation and stability studies of a hydrophilic decapeptide in different adjuvant drug delivery systems: a comparative study of PLGA nanoparticles versus chitosan-dextran sulphate microparticles versus DOTAP-liposomes. Int $J \quad$ Pharm. 2011;421(1):151-159. doi:10.1016/j. ijpharm.2011.09.011

15. Zupancic E, Curato C, Paisana M, et al. Rational design of nanoparticles towards targeting antigen-presenting cells and improved $\mathrm{T}$ cell priming. J Control Release. 2017;258:182-195. doi:10.1016/j. jconrel.2017.05.014

16. Park YM, Lee SJ, Kim YS, et al. Nanoparticle-based vaccine delivery for cancer immunotherapy. Immune Netw. 2013;13(5):177-183. doi:10.4110/in.2013.13.5.177

17. Prasad S, Cody V, Saucier-Sawyer JK, et al. Polymer nanoparticles containing tumor lysates as antigen delivery vehicles for dendritic cell-based antitumor immunotherapy. Nanomed-Nanotechnol. 2011;7 (1):1-10. doi:10.1016/j.nano.2010.07.002

18. Gupta RK, Singh M, O’Hagan DT. Poly(lactide-co-glycolide) microparticles for the development of single-dose controlled-release vaccines. Adv Drug Deliv Rev. 1998;32(3):225-246. doi:10.1016/ S0169-409X(98)00012-X

19. Athanasiou E, Agallou M, Tastsoglou S, et al. A poly(lactic-coglycolic) acid nanovaccine based on chimeric peptides from different Leishmania infantum proteins induces dendritic cells maturation and promotes peptide-specific IFNgamma-producing $\mathrm{CD} 8(+) \mathrm{T}$ cells essential for the protection against experimental visceral leishmaniasis. Front Immunol. 2017;8:684. doi:10.3389/ fimmu.2017.00684

20. Margaroni M, Agallou M, Athanasiou E, et al. Vaccination with poly (D,L-lactide-co-glycolide) nanoparticles loaded with soluble Leishmania antigens and modified with a TNFalpha-mimicking peptide or monophosphoryl lipid A confers protection against experimental visceral leishmaniasis. Int $J$ Nanomedicine. 2017;12:6169-6184. doi:10.2147/IJN.S141069

21. Agnihotri SA, Mallikarjuna NN, Aminabhavi TM. Recent advances on chitosan-based micro- and nanoparticles in drug delivery. J Control Release. 2004;100(1):5-28. doi:10.1016/j. jconrel.2004.08.010

22. Arca HC, Gunbeyaz M, Senel S. Chitosan-based systems for the delivery of vaccine antigens. Expert Rev Vaccines. 2009;8 (7):937-953. doi:10.1586/erv.09.47

23. Danesh-Bahreini MA, Shokri J, Samiei A, Kamali-Sarvestani E, Barzegar-Jalali M, Mohammadi-Samani S. Nanovaccine for leishmaniasis: preparation of chitosan nanoparticles containing Leishmania superoxide dismutase and evaluation of its immunogenicity in BALB/c mice. Int J Nanomedicine. 2011;6:835-842. doi:10.2147/ IJN.S16805
24. Wang Q, Wu L, Hasan MW, et al. Hepatocellular carcinoma-associated antigen 59 of Haemonchus contortus modulates the functions of PBMCs and the differentiation and maturation of monocyte-derived dendritic cells of goats in vitro. Parasit Vectors. 2019;12(1):105. doi:10.1186/s13071-019-3375-1

25. Garinot M, Fievez V, Pourcelle V, et al. PEGylated PLGA-based nanoparticles targeting $\mathrm{M}$ cells for oral vaccination. $J$ Control Release. 2007;120(3):195-204. doi:10.1016/j.jconrel.2007.04.021

26. Calvo P, RemunanLopez C, VilaJato JL, Alonso MJ. Chitosan and chitosan ethylene oxide propylene oxide block copolymer nanoparticles as novel carriers for proteins and vaccines. Pharmaceut Res. 1997;14(10):1431-1436. doi:10.1023/A:1012128907225

27. Debnath SK, Saisivam S, Debanth M, Omri A. Development and evaluation of Chitosan nanoparticles based dry powder inhalation formulations of Prothionamide. PLoS One. 2018;13(1). doi:10.1371/ journal.pone.0190976

28. Mirzaei F, Dounighi NM, Avadi MR, Rezayat M, New A. Approach to antivenom preparation using chitosan nanoparticles containing EchisCarinatus venom as a novel antigen delivery system. Iran J Pharm Res. 2017;16(3):858-867.

29. Zhao K, Chen G, Shi XM, et al. Preparation and efficacy of a live newcastle disease virus vaccine encapsulated in Chitosan nanoparticles. PLoS One. 2012;7(12):e53314. doi:10.1371/journal.pone.0053314

30. Xu YM, Du YM, Huang RH, Gao LP. Preparation and modification of N-(2-hydroxyl) propyl-3-trimethyl ammonium chitosan chloride nanoparticle as a protein carrier. Biomaterials. 2003;24 (27):5015-5022. doi:10.1016/S0142-9612(03)00408-3

31. Han K, Xu L, Yan R, Song X, Li X. Molecular cloning, expression and characterization of enolase from adult Haemonchus contortus. Res Vet Sci. 2012;92(2):259-265. doi:10.1016/j.rvsc.2011.03.008

32. Luo L, Qin T, Huang Y, et al. Exploring the immunopotentiation of Chinese yam polysaccharide poly(lactic-co-glycolic acid) nanoparticles in an ovalbumin vaccine formulation in vivo. Drug Deliv. 2017;24(1):1099-1111. doi:10.1080/10717544.2017.1359861

33. Salvador A, Sandgren KJ, Liang F, et al. Design and evaluation of surface and adjuvant modified PLGA microspheres for uptake by dendritic cells to improve vaccine responses. Int J Pharm. 2015;496 (2):371-381. doi:10.1016/j.ijpharm.2015.10.037

34. Zhang NZ, Xu Y, Wang M, et al. Vaccination with Toxoplasma gondii calcium-dependent protein kinase 6 and rhoptry protein 18 encapsulated in poly(lactide-co-glycolide) microspheres induces long-term protective immunity in mice. BMC Infect Dis. 2016;16:168. doi:10.1186/s12879-016-1496-0

35. Li Y, Yuan C, Wang LK, et al. Transmembrane protein 147 (TMEM147): another partner protein of Haemonchus contortus galectin on the goat peripheral blood mononuclear cells (PBMC). Parasite Vector. 2016;9. doi:10.1186/s13071-016-1640-0

36. Gadahi JA, Wang S, Bo G, et al. Proteomic analysis of the excretory and secretory proteins of Haemonchus contortus (HcESP) binding to goat PBMCs in vivo revealed stage-specific binding profiles. PLoS One. 2016;11(7):e0159796. doi:10.1371/journal.pone.0159796

37. Illum L, Jabbal-Gill I, Hinchcliffe M, Fisher AN, Davis SS. Chitosan as a novel nasal delivery system for vaccines. Adv Drug Deliver Rev. 2001;51(1-3):81-96. doi:10.1016/S0169-409X(01)00171-5

38. Wang JJ, Zeng ZW, Xiao RZ, et al. Recent advances of chitosan nanoparticles as drug carriers. Int J Nanomed. 2011;6:765-774.

39. Kanchan V, Katare YK, Panda AK. Memory antibody response from antigen loaded polymer particles and the effect of antigen release kinetics. Biomaterials. 2009;30(27):4763-4776. doi:10.1016/j.biomaterials.2009.05.075

40. Waeckerle-Men Y, Groettrup M. PLGA microspheres for improved antigen delivery to dendritic cells as cellular vaccines. Adv Drug Deliver Rev. 2005;57(3):475-482. doi:10.1016/j.addr.2004.09.007

41. Moore A, McGuirk P, Adams S, et al. Immunization with a soluble recombinant HIV protein entrapped in biodegradable microparticles induces HIV-specific CD8+ cytotoxic T lymphocytes and CD4+ Th1 cells. Vaccine. 1995;13(18):1741-1749. doi:10.1016/0264-410X(95) 00184-3 
42. Li P, Asokanathan C, Liu F, et al. PLGA nano/micro particles encapsulated with pertussis toxoid (PTd) enhances Th1/Th17 immune response in a murine model. Int J Pharm. 2016;513(1-2):183-190. doi:10.1016/j.ijpharm.2016.08.059

43. Feczko T, Toth J, Dosa G, Gyenis J. Optimization of protein encapsulation in PLGA nanoparticles. Chem Eng Process. 2011;50 (8):757-765. doi:10.1016/j.cep.2011.06.008

44. Hasan MW, Haseeb M, Ehsan M, et al. Nanoparticles (PLGA and Chitosan)-entrapped ADP-ribosylation factor 1 of Haemonchus contortus enhances the immune responses in ICR mice. Vaccines (Basel). 2020;8(4). doi:10.3390/vaccines8040726.

45. Huang H, Li Y, Qi X. Cytokine signaling in the differentiation of innate effector cells. JAKSTAT. 2013;2(1):e23531. doi:10.4161/ jkst.23531

46. Sommer MEL, Dalia RA, Nogueira AVB, et al. Immune response mediated by Th1/IL-17/caspase- 9 promotes evolution of periodontal disease. Arch Oral Biol. 2019;97:77-84. doi:10.1016/j. archoralbio.2018.09.009

47. Arango Duque G, Descoteaux A. Macrophage cytokines: involvement in immunity and infectious diseases. Front Immunol. 2014;5:491. doi:10.3389/fimmu.2014.00491

48. Li X, Liu X, Tian L, Chen Y. Cytokine-mediated immunopathogenesis of hepatitis B virus infections. Clin Rev Allergy Immunol. 2016;50(1):41-54. doi:10.1007/s12016-014-8465-4

49. Jazaeri EO, Mahdavi A, Abdoli A. Formulation of chitosan with the polyepitope HIV-1 protein candidate vaccine efficiently boosts cellular immune responses in mice. Pathog Dis. 2017;75(8). doi:10.1093/ femspd/ftx098

50. Luo L, Zheng SS, Huang YF, et al. Preparation and characterization of Chinese yam polysaccharide PLGA nanoparticles and their immunological activity. Int $J$ Pharmaceut. 2016;511(1):140-150. doi:10.1016/j.ijpharm.2016.06.130

51. Gazzinelli R, Xu YH, Hieny S, Cheever A, Sher A. Simultaneous depletion of $\mathrm{Cd} 4+$ and $\mathrm{Cd} 8+$ lymphocytes-T is required to reactivate chronic infection with Toxoplasma-gondii. J Immunol. 1992;149 (1):175-180.

52. Jordan KA, Hunter CA. Regulation of CD8+ T cell responses to infection with parasitic protozoa. Exp Parasitol. 2010;126 (3):318-325. doi:10.1016/j.exppara.2010.05.008

53. Banchereau J, Briere F, Caux C, et al. Immunobiology of dendritic cells. Annu Rev Immunol. 2000;18:767-811. doi:10.1146/annurev. immunol.18.1.767

54. Merad M, Sathe P, Helft J, Miller J, Mortha A. The dendritic cell lineage: ontogeny and function of dendritic cells and their subsets in the steady state and the inflamed setting. Annu Rev Immunol. 2013;31:563-604. doi:10.1146/annurev-immunol-020711-074950

55. Grosche L, Knippertz I, König C, et al. The CD83 molecule - an important immune checkpoint. Front Immunol. 2020;11:721. doi:10.3389/fimmu.2020.00721
56. Baravalle G, Park H, McSweeney M, et al. Ubiquitination of CD86 is a key mechanism in regulating antigen presentation by dendritic cells. J Immunol. 2011;187(6):2966-2973. doi:10.4049/jimmunol.1101643

57. Galassie AC, Link AJ. Proteomic contributions to our understanding of vaccine and immune responses. Proteom Clin Appl. 2015;9(11-12):972-989. doi:10.1002/prca.201500054

58. Hajavi J, Ebrahimian M, Sankian M, Khakzad MR, Hashemi M. Optimization of PLGA formulation containing protein or peptide-based antigen: recent advances. J Biomed Mater Res A. 2018;106(9):2540-2551. doi:10.1002/jbm.a.36423

59. Muxika A, Etxabide A, Uranga J, Guerrero P, de la Caba K. Chitosan as a bioactive polymer: processing, properties and applications. Int J Biol Macromol. 2017;105(Pt 2):1358-1368. doi:10.1016/j. ijbiomac.2017.07.087

60. Durán V, Yasar H, Becker J, et al. Preferential uptake of chitosan-coated PLGA nanoparticles by primary human antigen presenting cells. Nanomedicine. 2019;21:102073. doi:10.1016/j. nano.2019.102073

61. Lima IA, Khalil NM, Tominaga TT, Lechanteur A, Sarmento B, Mainardes RM. Mucoadhesive chitosan-coated PLGA nanoparticles for oral delivery of ferulic acid. Artif Cells Nanomed Biotechnol. 2018;46(sup2):993-1002. doi:10.1080/21691401.2018.1477788

62. Miele D, Rossi S, Sandri G, et al. Chitosan oleate salt as an amphiphilic polymer for the surface modification of Poly-Lactic-Glycolic Acid (PLGA) nanoparticles. preliminary studies of mucoadhesion and cell interaction properties. Mar Drugs. 2018;16(11):447. doi:10.3390/md16110447

63. Mustafa S, Devi VK, Pai RS. Effect of PEG and water-soluble chitosan coating on moxifloxacin-loaded PLGA long-circulating nanoparticles. Drug Deliv Transl Res. 2017;7(1):27-36. doi:10.1007/s13346-016-0326-7

64. Nie H, Lee LY, Tong H, Wang CH. PLGA/chitosan composites from a combination of spray drying and supercritical fluid foaming techniques: new carriers for DNA delivery. J Control Release. 2008;129 (3):207-214. doi:10.1016/j.jconrel.2008.04.018

65. Huang WF, Tsui CP, Tang CY, Yang M, Gu L. Surface charge switchable and $\mathrm{pH}$-responsive chitosan/polymer core-shell composite nanoparticles for drug delivery application. Compos Part B Eng. 2017;121:83-91. doi:10.1016/j.compositesb.2017.03.028

66. Pola CC, Moraes ARF, Medeiros EAA, Teófilo RF, Soares NFF, Gomes CL. Development and optimization of $\mathrm{pH}$-responsive PLGA-chitosan nanoparticles for triggered release of antimicrobials. Food Chem. 2019;295:671-679. doi:10.1016/j.foodchem.2019.05. 165
International Journal of Nanomedicine

\section{Publish your work in this journal}

The International Journal of Nanomedicine is an international, peerreviewed journal focusing on the application of nanotechnology in diagnostics, therapeutics, and drug delivery systems throughout the biomedical field. This journal is indexed on PubMed Central, MedLine, CAS, SciSearch ${ }^{\circledR}$, Current Contents ${ }^{\circledR} /$ Clinical Medicine,
Journal Citation Reports/Science Edition, EMBase, Scopus and the Elsevier Bibliographic databases. The manuscript management system is completely online and includes a very quick and fair peer-review system, which is all easy to use. Visit http://www.dovepress.com/ testimonials.php to read real quotes from published authors. 